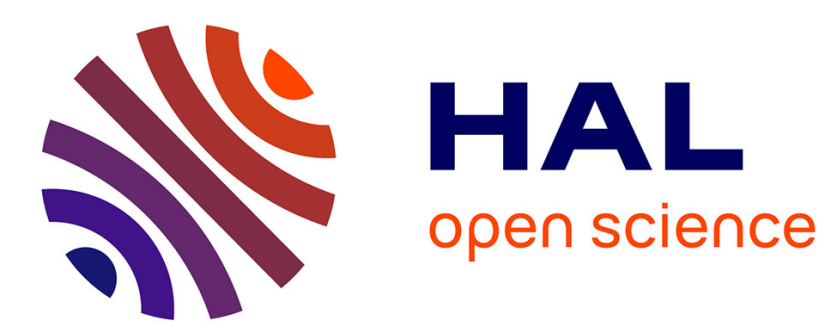

\title{
Quantification of Thiram in Honeybees: Development of a Chemiluminescent ELISA
}

Stefano Girotti, Elisabetta Maiolini, Severino Ghini, Elida Ferri, Fabiana Fini, Patrice Nodet, Sergei Eremin

\section{- To cite this version:}

Stefano Girotti, Elisabetta Maiolini, Severino Ghini, Elida Ferri, Fabiana Fini, et al.. Quantification of Thiram in Honeybees: Development of a Chemiluminescent ELISA. Analytical Letters, 2008, 41 (1), pp.46-55. 10.1080/00032710701748291 . hal-00519713

\section{HAL Id: hal-00519713 \\ https://hal.univ-brest.fr/hal-00519713}

Submitted on 21 Sep 2010

HAL is a multi-disciplinary open access archive for the deposit and dissemination of scientific research documents, whether they are published or not. The documents may come from teaching and research institutions in France or abroad, or from public or private research centers.
L'archive ouverte pluridisciplinaire HAL, est destinée au dépôt et à la diffusion de documents scientifiques de niveau recherche, publiés ou non, émanant des établissements d'enseignement et de recherche français ou étrangers, des laboratoires publics ou privés. 


\title{
Quantification of Thiram in Honeybees: Development of a Chemiluminescent ELISA
}

\author{
Stefano Girotti, Elisabetta Maiolini, Severino Ghini, Elida Ferri, Fabiana Fini \\ Dipartimento di Scienza dei Metalli, Elettrochimica e Tecniche Chimiche, Università di \\ Bologna, via San Donato 15, 40127 Bologna, Italy
}

\section{Patrice Nodet}

Laboratoire de Biodiversité et Ecologie Microbienne, ESMISAB, Technopôle Brest-Iroise, 29280 Plouzané, France

\section{Sergei Eremin}

Department of Chemical Enzymology, Faculty of Chemistry, M.V. Lomonosov Moscow State University, Moscow 119992, Russia

\begin{abstract}
A Chemiluminescence Enzyme-Linked Immuno-Sorbent Assay (CL-ELISA) for determination and quantification of the fungicide thiram in honeybees was developed in an indirect competitive format. The assay was optimized by determining: the optimal coating conjugate concentration and anti-thiram antiserum dilution, the effect of the incubation time on the competitive step, the tolerance to organic solvents. $\mathrm{The}^{\mathrm{IC}} \mathrm{C}_{50}$ and the limit of detection (LOD) values were $60 \mathrm{ng} \mathrm{mL}^{-1}$ and $9 \mathrm{ng} \mathrm{mL}^{-1}$, respectively, similar to those of colorimetric ELISA with a calibration range of $9-15,000 \mathrm{ng} \mathrm{mL}^{-1}$. Cross reactivity of some related compounds such as some dithiocarbamates, a thiocarbamate, the ethylenethiourea and the tetramethylthiourea were tested. The assay was then applied to honeybees sample extracts obtained by using the liquid-liquid extraction or the graphitized carbon-based solid phase extraction.
\end{abstract}


The calibration curves in honeybee extracts from liquid-liquid procedure gave an $\mathrm{IC}_{50}$ of 141 $\mathrm{ng} \mathrm{mL} \mathrm{m}^{-1}$ and a LOD of $17 \mathrm{ng} \mathrm{mL}^{-1}$. In case of extracts obtained by SPE these values were 139 ng $\mathrm{mL}^{-1}$ and $15 \mathrm{ng} \mathrm{mL}^{-1}$, respectively. The average recovery value from honeybee extracts spiked with $75 \mathrm{ng} \mathrm{mL}^{-1}$ of thiram was $72 \%$ for SPE, higher than for liquid-liquid extraction $(60 \%)$. On the opposite, when the honeybees were directly spiked with 2 and $10 \mathrm{ppm}$ the average recovery was higher for liquid-liquid extraction (54\%), than for SPE (31\%). Finally, the assay was applied to honeybee samples collected during monitoring activities in Italy and Russia.

Key words: Thiram, Chemiluminescence, ELISA, Honeybees

Running title: Quantification of Thiram in Honeybees

Super title: Bioanalytical or Environmental Analysis

Address correspondence to Stefano Girotti, Dipartimento di Scienza dei Metalli, Elettrochimica e Tecniche Chimiche, Università di Bologna, via San Donato 15, 40127 Bologna, Italy, E-mail: stefano.girotti@,unibo.it 


\section{INTRODUCTION}

Thiram (tetramethylthiuram disulfide) [bis(dimethylthiocarbamyl)disulfide] is a dithiocarbamate, a wide-spectrum, non-systemic, fungicide. It is commonly applied in agriculture and horticulture as protectant on foliage and fruits, for seed treatment on maize, cotton, cereals and as a vulcanizing agent in the rubber industry. On humans thiram has been employed against scabies, as a sunscreen agent or as a bactericide applied directly to the skin in soaps. It can be also present in the environment as an oxidation product of two other widely employed fungicides, ferbam and ziram and it can persist in soil for several weeks (Sharma 2003).

Several toxic effects of thiram have been reported: skin lesions, including hand eczema or dermatitis, among exposed workers (Saunders 2001); hepatic dysfunctions, mainly due to the carbon disulfide produced during thiram decomposition (Edwards 1991); neurotoxicity (Sook Han 2003) and citotoxicity in rat (Cereser 2001).

Various analytical methods to determine both qualitatively and quantitatively thiram have been reported, based on spectrophotometric (Tunceli 2001) chromatographic (Gustafsson on 1981; Brandsteterova 1986) and immuno-enzymatic (Gueguen 2000; Queffelec 2001; Aulakh 2005) techniques.

Due to the rapid decomposition of the dithiocarbamate molecule the detection methods are usually based on the measurement of the carbon disulfide produced, but this make impossible to differentiate among the various dithiocarbamates (Hill 1992, Royer 2001).

The methods available to determine dithiocarbamates without degradation usually involve high performance liquid chromatography (HPLC) or gas chromatography (GC), time consuming, expensive and specialized personnel requiring techniques. 
Using specific antibodies the immunological assays allow to overcome these problems, offering a very useful tool for environmental analysis in general, and for pesticides detection in particular (Lee 2001; Eremin 2003; Wang 2007).

The employment of pollinators, especially honeybees, in environmental studies is due to their capacity to reveal chemical impairment of the environment both by a higher mortality (in the case of pesticides) and by retaining on their body the particles suspended in the air or on the plants (Porrini 2002). The importance of honeybees as bioindicators for environmental pollution is well described in literature as well as their role early warning system (Porrini 2003; Ghini 2004).

Here we describe the development of a chemiluminescent enzyme-linked immunosorbent assay (CL-ELISA) that employs luminol, horseradish peroxidase as labeling enzyme (Botchkareva 2003; Dotsikas 2007; Marquette 2006), and polyclonal antibodies for the detection and quantification of thiram in honeybee extracts for the rapid and sensitive screening of a large number of samples. The starting basis of this development was the colorimetric ELISA for thiram already reported by Queffelec (2001).

\section{EXPERIMENTAL}

\section{Reagents}

Standard pesticides were purchased from Dr Ehrenstorfer GmbH (Augsburg, Germany). Peroxidase-labeled goat anti-rabbit immunoglobulins were from Dako (Glostrup, Denmark). All chemicals and organic solvents used were of reagent grade, or better. Black polystyrene high-binding plates were from Costar (Cambridge, Massachusetts). The hapten-protein conjugate (OVA-2C) and the polyclonal antibodies against thiram were prepared as previously described (Gueguen 2000). 


\section{CL-ELISA}

Assays were performed in 96-well microplates as indirect competitive format. Immunoreagent optimum concentrations were determined by bidimensional titrations in the concentration range $0.01-0.6 \mu \mathrm{g} \mathrm{mL}^{-1}$ for OVA-2C and at dilution ratio for anti-thiram serum in the range $1 / 30,000-1 / 90,000$. The effect of incubation time with anti-thiram serum was determined by testing different incubation time $(30,60,90,120 \mathrm{~min})$ for the competitive step. To assess the tolerance of the assay components to the organic solvents acetone and methanol were added at four different final concentrations: 3, 5, 10 and 20\%.

According to Dako (Glostrup, Denmark) dilution guidelines (www.dako.it) we used the peroxidase-labeled goat anti-rabbit immunoglobulins diluted 1/2,000.

Plates were coated overnight with $100 \mu \mathrm{L}$ per well of OVA-hapten $2 \mathrm{C}\left(0.6 \mu \mathrm{g} \mathrm{mL}^{-1}\right)$ in carbonate-bicarbonate buffer $0.05 \mathrm{M} \mathrm{pH} 9.6$, which corresponded to $0.06 \mu \mathrm{g} \mathrm{mL}^{-1}$ of OVAhapten $2 \mathrm{C}$ per well.

Plates were then washed three times in a WellWash4 from Labsystem (Sweden) with $0.01 \mathrm{M}$, pH 7.4 phosphate buffered saline (PBS: $1.5 \mathrm{mM} \mathrm{KH}_{2} \mathrm{PO}_{4}, 8 \mathrm{mM} \mathrm{Na}_{2} \mathrm{HPO}_{4}, 2.7 \mathrm{mM}$ $\mathrm{KCl}, 137 \mathrm{mM} \mathrm{NaCl}$ and $0.02 \% \mathrm{NaN}_{3}$ ) supplemented with $0,05 \%$ Tween 20, as washing solution and after addition of $50 \mu \mathrm{L}$ per well of standard or sample plus $50 \mu 1$ per well of antiserum $1 / 30,000$ in $2 \mathrm{x}$ fish gelatine solution in PBS (PBS-G) were incubated for $1.5 \mathrm{~h}$ at room temperature. After washing, $50 \mu \mathrm{l}$ per well of peroxidase-labeled goat anti-rabbit immunoglobulin, diluted $1 / 2,000$ in $1 \mathrm{x}$ PBS-G, were added and incubated again for $1.5 \mathrm{~h}$ at room temperature. After washing, $100 \mu \mathrm{L}$ per well of a substrate solution ( $1 \mathrm{mM}$ luminol, 0.5 $\mathrm{mM}$ p-iodophenol, $1 \mathrm{mM} \mathrm{H}_{2} \mathrm{O}_{2}$ in $0.2 \mathrm{M}$ borate buffer, $\mathrm{pH} 8.5$ ) were added and intensity of chemiluminescence emission, expressed as relative light units (RLU), immediately measured in a Victor microplate luminometer (Wallac, Finland). 
To allow a direct comparison of the various standard curves, the absorbance data are normalized between the $100 \%$, which corresponds to the absorption of a blank control $\left(\mathrm{A}_{0}\right)$ and the $0 \%$, which corresponds to the absorbance of a sample with an excess of standard compound $\left(\mathrm{A}_{\text {excess }}\right)$. The normalization is performed according to the following expression: $\% \mathrm{~B} / \mathrm{B}_{0}=100\left(\mathrm{~A}-\mathrm{A}_{\text {excess }}\right) /\left(\mathrm{A}_{0}-\mathrm{A}_{\text {excess }}\right)$.

RLU values from standard samples were mathematically fitted to a four parameter logistic equation (Botchkareva 2003) by using Sigmaplot ${ }^{\circledR}$ software (SPSS), version 8.0.

The limit of detection (LOD) for CL-ELISA was calculated as the analyte concentration that reduced the signal to $90 \%$ of the maximum. The $\mathrm{IC}_{50}$ value was calculated as the analyte concentrations that reduced the assay signal to the $50 \%$ of the maximum.

\section{Honeybees' extraction}

Before analysis, honeybees were lyophilized by using a lyophilizer (HETOSICC Cooling Condenser) and stored at $-5^{\circ} \mathrm{C}$. Two extraction methods were used: a liquid-liquid extraction (LLE), as previously described (Ghini 2004; Rossi 2001), and a graphitized carbon-based solid-phase extraction (SPE) (Girotti 2005). In the solid-phase procedure the extraction is performed during the lyophilisation step, by using a home-made cartridge containing graphitized-carbon (Carbopack Y 40/60, Mesh, Supelco) inserted in the lyophilizer.

Reference blank samples were obtained by extracting honeybees which had died during the winter season, when no agricultural treatments are performed, so they were surely notcontaminated, as it was also confirmed by gas chromatographic analyses (Ghini 2004; Rossi 2001; Hill 1992).

\section{Spiked honeybees}


To evaluate the accuracy of the extraction procedure the honeybees were contaminated with 2 and $10 \mathrm{ppm}$ of pesticide. For a homogeneous distribution on the body of the honeybees, the pesticide was placed on each one by using an insulin syringe. After the contamination process, the honeybees have been lyophilized.

\section{Honeybees sample from monitoring control}

52 samples of honeybees, collected during monitoring activities in Italy and Russia were analyzed by ELISA, to check the thiram content, and by gas chromatography as described by Hill (1992) and Rossi (2001), to determine the presence of thiram and other pesticides traces. The 27 Italian samples, from environmental monitoring stations placed in the countryside around Bologna, were provided by the association "La Carlina". The 25 samples from Russia were from five different sites, near and far from Moscow, and were provided by University of Moscow.

\section{RESULTS AND DISCUSSION}

Using standard solution of thiram we determined that the better assay conditions were: $0.6 \mu \mathrm{g}$ $\mathrm{mL}^{-1}$ of OVA-2C (0.06 $\mu \mathrm{g}$ per well), anti-thiram serum dilution of 1/30,000, and $90 \mathrm{~min}$ of incubation for the competition step.

The influence of solvents was studied using methanol and acetone (Fig. $1 \mathrm{~A}$ and $\mathrm{B}$ ). The $\mathrm{IC}_{50}$ values and RLU max for both solvents at each concentration were compared. Methanol lead to a decrease of the assay sensitivity (Fig. 1B) and the addition of 3\% (final concentration) of acetone was chosen as the optimal condition for the CL-ELISA of thiram (Fig. 1A).

Under these condition the $\mathrm{IC}_{50}$ and the LOD values were, respectively, $60 \mathrm{ng} \mathrm{mL}{ }^{-1}$ and $9 \mathrm{ng} \mathrm{mL} \mathrm{m}^{-1}$, showing a similar sensitivity with respect to the colorimetric assay reported by 
Queffelec (2001) (34 $\mathrm{ng} \mathrm{mL} \mathrm{m}^{-1}$ and $5 \mathrm{ng} \mathrm{mL}^{-1}$, respectively). Using a standard solution with a thiram content of $75 \mathrm{ng} \mathrm{mL}^{-1}$ the measured content obtained by CL-ELISA was in the range of $95-100 \%$, with an imprecision (coefficient of variation $(\mathrm{CV})$ ) of $12 \%$. The calibration curve concentration range of thiram using the CL-ELISA was $9-15,000 \mathrm{ng} \mathrm{mL}^{-1}$.

Usually the immunoassays with chemiluminescent detection, with respect to the colorimetric ones, allow to reach better sensitivity or to use lower amounts of the immunoreagents (Mickova 2005), but this was not the case. Probably this particular behaviour can be ascribed to the characteristics of the antibodies used in this assay and changes due to the time elapsed from production. This antibody change was confirmed by application of colorimetric ELISA on thiram determination in our laboratory: the sensitivity and LOD were worse than those obtained by Queffelec (2001).

The cross reactivity of some related compounds such as: tetramethylthiuram disulfide, dimethyl dithiocarbamic acid sodium salt, dimethyl dithiocarbamic acid zinc salt (ziram) and zineb (dithiocarbamates), molinate (a thiocarbamate), ethylenethiourea and tetramethylthiourea was tested. A little cross reactivity was observed only for ziram (26\%), and tetramethylthiuram disulfide (28\%), as shown in Table 1 . Those results are less or more similar to colorimetric ELISA, and this could be ascribed to the same change of antibodies due to their storage and time-life.

To evaluate the matrix effect the extraction was first carried out on not contaminated honeybee samples, using the two extractions methods. The honeybees extracts, pesticide-free, were diluted 100 fold to reduce to acceptable levels the matrix effect, as already reported by Girotti (2005), and then used as diluting solution in CL-ELISA.

Fig. 2 shows the mean calibration curves obtained in different solutions: water/acetone $(97: 3, \mathrm{v} / \mathrm{v})$; water/liquid-liquid extract 1:100 in acetone $(97: 3, \mathrm{v} / \mathrm{v})$; water/acetone graphitized carbon extract 1:100 in acetone $(97: 3, \mathrm{v} / \mathrm{v})$. 
The two methods shown different matrix effects that were greater for the solutions resulting from the liquid-liquid extraction than for those from the graphitized carbon procedure.

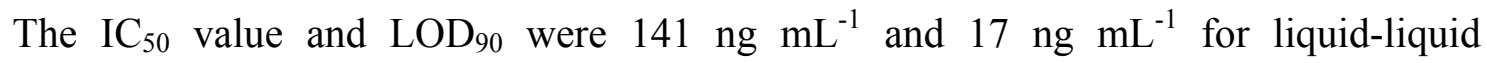
extraction, $139 \mathrm{ng} \mathrm{mL}^{-1}$ and $15 \mathrm{ng} \mathrm{mL}^{-1}$ for graphitized carbon extraction (Fig. 2).

To further evaluate the matrix effect, the pesticide-free honeybee extracts, obtained by both methods, were spiked with exact amount of thiram $\left(75 \mathrm{ng} \mathrm{mL}^{-1}\right)$. The measured amount was little higher in the extracts obtained by the SPE method (72\%), than in those by the LLE $(60 \%)$, probably because of the lowest matrix effect associated to the SPE extracts. The values of imprecision $(\mathrm{CV})$ were similar: $11 \%$ for SPE and 14\% for LLE method, respectively.

To calculate the amount of pesticide recovered by each extraction procedure, the spiked honeybees, at 2 and $10 \mathrm{ng} \mathrm{mL}^{-1}$ levels, were extracted. It was possible to measure recovered amounts of the analyte only from the samples spiked with $10 \mathrm{ng} \mathrm{mL} L^{-1}$. The percentage was higher for liquid-liquid extraction, 54\%, than for SPE, 31\%, underlying the difficulties due to the complexity of the honeybee matrix. Moreover, the poor volatility of thiram could explain the low recovery values obtained by the SPE, performed during lyophilisation. The CVs were $15 \%$ for LLE and $18 \%$ for SPE method.

Finally we applied the CL-ELISA to real honeybees samples, 27 collected in Italy and 25 in Russia. By using the liquid-liquid extraction all Italian samples resulted negatives and only three of the Russian ones were positives, with amounts of thiram ranging between 17 and $34 \mathrm{ng} \mathrm{mL} \mathrm{m}^{-1}$. These results were confirmed by GC analyses; the three Russian samples resulted to contain higher amounts of pesticide (the range was $32-67 \mathrm{ng} \mathrm{mL} L^{-1}$ ), due to the fact that the thiram is determined as carbon disulfide (Hill 1992). By this method not only thiram is determined, but also other sulphur-containing pesticides. 
When the graphitized carbon extraction was employed all samples, Italian and Russian, resulted negatives, depending on the extraction efficiency, since these results were confirmed also by GC.

\section{CONCLUSIONS}

The competitive CL-ELISA developed for the detection of thiram in honeybees showed great specificity and a quite good sensitivity, even if the $\mathrm{IC}_{50}$ and LOD values were about twice than those reported by Queffelec (2001).

Thiram must be extracted from honeybees by organic solvents, which could decrease sensitivity of immunoassay. For this reason we used ELISA-CL, which was optimized for Thiram detection in acetone extracts.

The analysis of this compound in honeybee samples posed several problems due both to the instability of thiram and to the complexity of the matrix. These problems were serious enough to do not permit to obtain good recovery and sensitivity.

For extracts obtained by both methods some problems due to the matrix effect can be overcome by a 100 fold dilution, that allowed to obtain reproducible results, although this resulted in a lighter decrease of the sensibility. The dilution reduced the concentration of interfering substances extracted with thiram, and this can explain the good recovery values obtained for thiram added to the extracts.

On the other hand, the determination of thiram in real samples appears to be even more complicated. The time and/or the solvents required for the liquid-liquid extraction probably cause the degradation of thiram, allowing the detection of the compound only when present in quantity bigger than $10 \mathrm{ng} \mathrm{mL} L^{-1}$, whereas the poor volatility of the molecule make the solid phase extraction method useless. 
It is important to underline that the developed chemiluminescent assay, using specific antibodies, is able to detect the thiram as itself and not as a generic residue of degradation, and that it is a semi quantitative method that allows a rapid and easy screening of honeybee samples.

\section{ACKNOWLEDGMENTS}

This work was supported by grant from the University of Bologna (Fundamental Oriented Research). 


\section{REFERENCES}

Aulakh, J.S., Malik, A.K., and Mahajan, R.K. 2005. Solid phase microextraction-high pressure liquid chromatographic determination of nabam, thiram and azamethiphos in water samples with UV detection. preliminary data. Talanta, 66: 266-270.

Botchkareva, A.E., Eremin, S.A., Montoya, A., Manclus, J.J., Mickova, B., Rauch, P., Fini, F., and Girotti, S. 2003. Development of chemiluminescent ELISAs to DDT and its metabolites in food and environmental samples. J. Immunol. Methods, 283: 45-47.

Brandsteterova, E., Lehotay, J., Liska, O., and Garaj, J. 1986. High-performance liquid chromatographic determination of dimethyldithiocarbamate residues in some agricultural products. J. Chromatogr., 354: 375-381.

Cereser, C., Boger, S., Parvaz, P., and Revol, A. 2001. Thiram-induced cytotoxicity is accompanied by a rapid and drastic oxidation of reduced glutathione with consecutive lipid peroxidation and cell death. Toxicology, 163: 153-162.

Dotsikas, Y., and Loukas, Y.L. 2007. Effect of the luminol signal enhancer selection on the curve parameters of an immunoassay and the chemiluminescence intensity and kinetics. Talanta, 71: 906-910.

Edwards, I.R, Ferry D.G., and Temple, W.A. 1991. Fungicides and related compounds. In Handbook of Pesticide Toxicology, Vol. 3, Hayes, W. J. and Laws E. R. (eds.). New York: Academic Press. 
Eremin, S.A, and Smith, D.S. 2003. Fluorescence polarization immunoassays for pesticides. Comb. Chem. High Throughput Screen, 6: 257-266.

Ghini, S., Fernández, M., Picó, Y., Marín, R., Fini, F., Mañes, J. and Girotti, S. 2004. Occurrence and distribution of pesticides in the province of Bologna, Italy, using honeybees as bioindicators. Arch. Environ. Contam. Toxicol., 47: 479-488.

Girotti, S., Fini, F., Ghini, S., Totti, S., Ferri, E., Mercader, J.V., Montoya A., and Eremin, S.A. 2005. Development of a chemiluminescent immunoassay for the detection of azinphosmethyl in honeybees. Ovidius Univ. Annals Chem., 16: 167-169.

Gueguen, F., Boisde, F., Queffelec, A.L., Haelters, J.P., Thouvenot, D., Corbel, B., and Nodet, P. 2000. Hapten synthesis for the development of a competitive inhibition enzymeimmunoassay for thiram. J. Agric. Food Chem., 48: 4492-4499.

Gustafsson, K.H., and Thompson, R.A. 1981. High-pressure liquid chromatography determination of fungicidal dithiocarbamates. J. Agric. Food Chem., 29: 729-732.

\section{http://www.dako.it/prod downloadpackageinsert.pdf?objectid=104817001}

Lee, N.A., and Kennedy, I.R. 2001. Environmental monitoring of pesticides by immunoanalytical techniques: validation, current status, and future perspectives. J. $A O A C$ Int., 84: 1393-1406. 
Marquette, C.A., and Blum, L.J. 2006. Applications of the luminol chemiluminescent reaction in analytical chemistry. Anal. Bioanal. Chem., 385: 546-554.

Mickova, B., Kovalczuk, T., Rauch, P., Moreno, M.J., Abad. A., Montoya, A., Ferri, E., Fini, F., and Girotti, S.2005. Analytical performances of validated chemiluminescent enzyme immunoassays to detect N-methylcarbamate pesticides. Anal. Chim. Acta, 528: 243-248.

Porrini, C., Ghini, S., Girotti, S., Sabatini, A.G., Gattavecchia, E., and Celli, G. 2002. In Honey bees: estimating the environmental impact of chemicals. J. Devillers and M.H. PhamDelègue (eds.), London: Routledge-Taylors \& Francis Group, p. 186-247.

Porrini, C., Sabatini A.G., Girotti, S., Ghini, S., Medrzycki, P., Grillenzoni, F., Bortolotti, L., Gattavecchia, E., and Celli, G. 2003. Honeybees and bee products as monitors for the environmental contamination. Apiacta, 38: 63-70.

Queffelec, A.L, Boisdé, F., Larue, J.P., Haelters, J.P., Corbel, B., Thouvenot, D., and Nodet, P. 2001. Development of an immunoassay (ELISA) for the quantification of Thiram in lettuce. J. Agric. Food Chem., 49: 1675-1680.

Rossi, S., Dalpero, A.P., Ghini, S., Colombo, R., Sabatini, A.G., and Girotti, S. 2001. Multiresidual method for the gas chromatographic analysis of pesticides in honeybees cleaned by gel permeation chromatography. J. Chromatogr., 905: 223-232.

Sharma, K.V., Aulakh, J.S., and Malik, A.K. 2003. Thiram: degradation, applications and analytical methods. J. Environ. Monit., 5: 717-723. 
Saunders, H., and Watkins, F. 2001. Allergic contact dermatitis due to thiuram exposure from a fungicide. Australas. J. Dermatol,. 42: 217-218.

Sook Han, M., Shin, K.J., Kim, Y.H., Kim, S.H., Lee, T., Kim, E., Ho Ryu, S., and Suh, P.G. 2003. Thiram and ziram stimulate non-selective cation channel and induce apoptosis in PC12 cells. Neurotoxicol., 24: 425-434.

Tunceli, A., Bag, H., and Turker, A.R. 2001. Spectrophotometric determination of some pesticides in water samples after preconcentration with Saccharomyces cerevisiae immobilized on sepiolite. Fresenius J. Anal. Chem., 371: 1134-1138.

Wang, S.T, Gui, W.J., Guo, Y.R., and Zhu, G.N. 2007. Preparation of a multi-hapten antigen and broad specificity polyclonal antibodies for a multiple pesticide immunoassay. Anal. Chim. Acta, 587: 287-292. 
Legends to the Figures of the manuscript

Stefano Girotti, Elisabetta Maiolini, Severino Ghini, Elida Ferri, Fabiana Fini, Patrice Nodet, Sergei Eremin. "QUANTIFICATION OF THIRAM IN HONEYBEES: DEVELOPMENT OF A CHEMILUMINESCENT ELISA"

Figure 1A. Influence of acetone concentration on the immunoassay: - - - thiram standards in $3 \%$ acetone; $-\boldsymbol{\nabla}$ - thiram standards in 5\% acetone; - $\mathbf{-}$ - thiram standards in 10\% acetone; Thiram standards in $20 \%$ acetone.

Figure 1B. Influence of methanol concentration on the immunoassay: - $\bullet$-thiram standards in 3\% methanol; - $\mathbf{\nabla}$ - thiram standards in 5\% methanol; - $\mathbf{- m}$ - thiram standards in 10\% methanol; - thiram standards in $20 \%$ methanol.

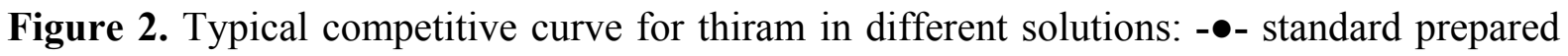
in water/acetone; $\mathbf{- \nabla}$ - standard prepared in water/acetone honeybees liquid-liquid extract; standard prepared in water/acetone honeybees graphitized carbon extract. 
Table 1. Percentage of cross reactivity of some dithiocarbamates and related compounds

\begin{tabular}{|c|c|c|}
\hline COMPOUNDS & $\mathrm{IC}_{50}\left(\mu \mathrm{g} \mathrm{mL}^{-1}\right)$ & Cross reactivity (\%) \\
\hline Thiram & $0.14 \pm 0.03$ & 100 \\
\hline Dimethyldithiocarbamic acid sodium salt & $0.63 \pm 0.03$ & 30 \\
\hline Dimethyldithiocarbamic acid zinc salt (Ziram) & $0.54 \pm 0.02$ & 26 \\
\hline Zineb & $>500$ & ND* \\
\hline Maneb & $>500$ & ND* \\
\hline Molinate & $>500$ & ND* \\
\hline Ethylenethiourea & $>500$ & 28 \\
\hline Tetramethylthiuram disulfide & $0.40 \pm 0.02$ & \\
\hline
\end{tabular}

*not detectable 


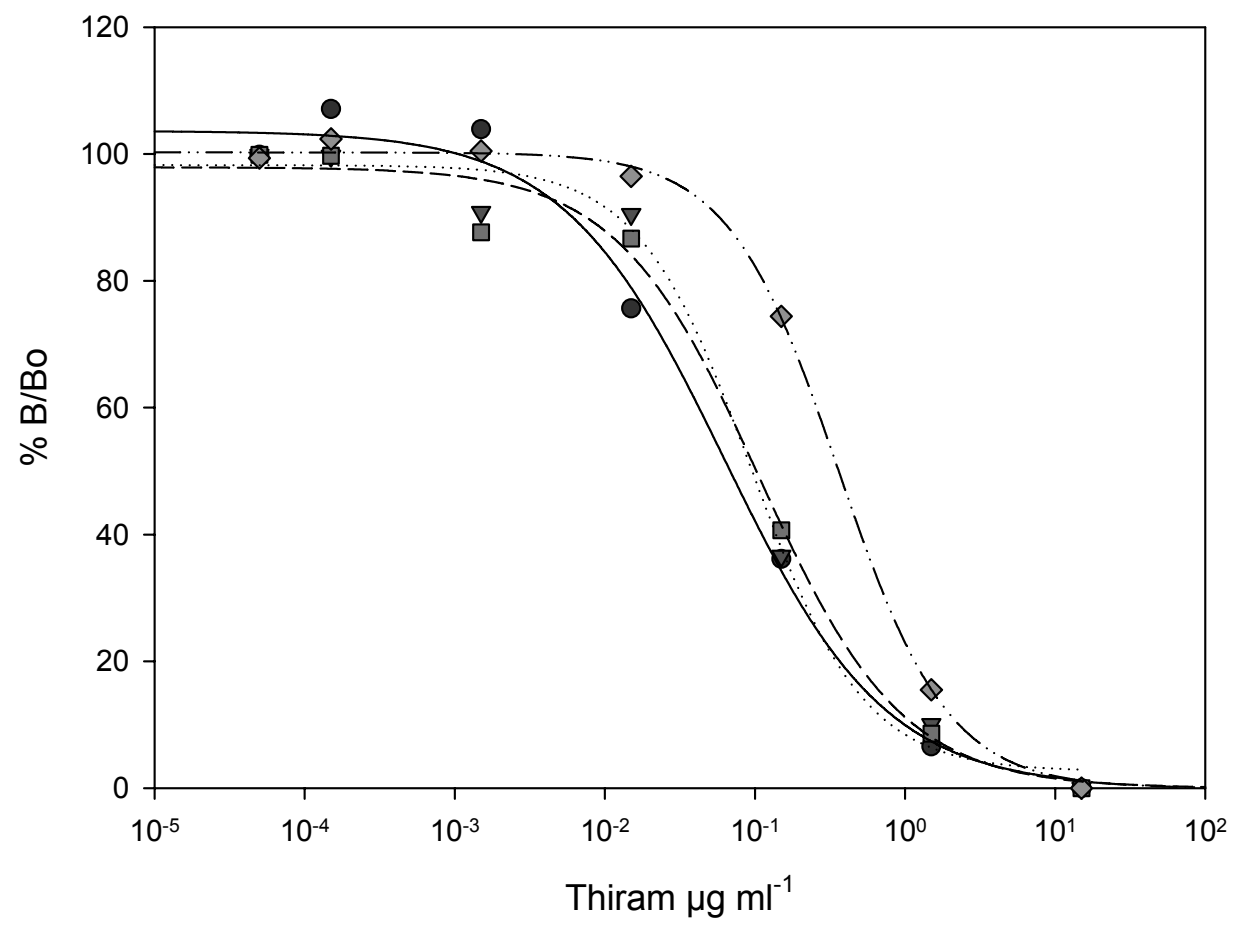

Figure 1A. Influence of acetone concentration on the immunoassay: - $\bullet-$ thiram standards in $3 \%$ acetone; $-\boldsymbol{\nabla}$ - thiram standards in 5\% acetone; - $\mathbf{-}$ - thiram standards in 10\% acetone; thiram standards in $20 \%$ acetone. 


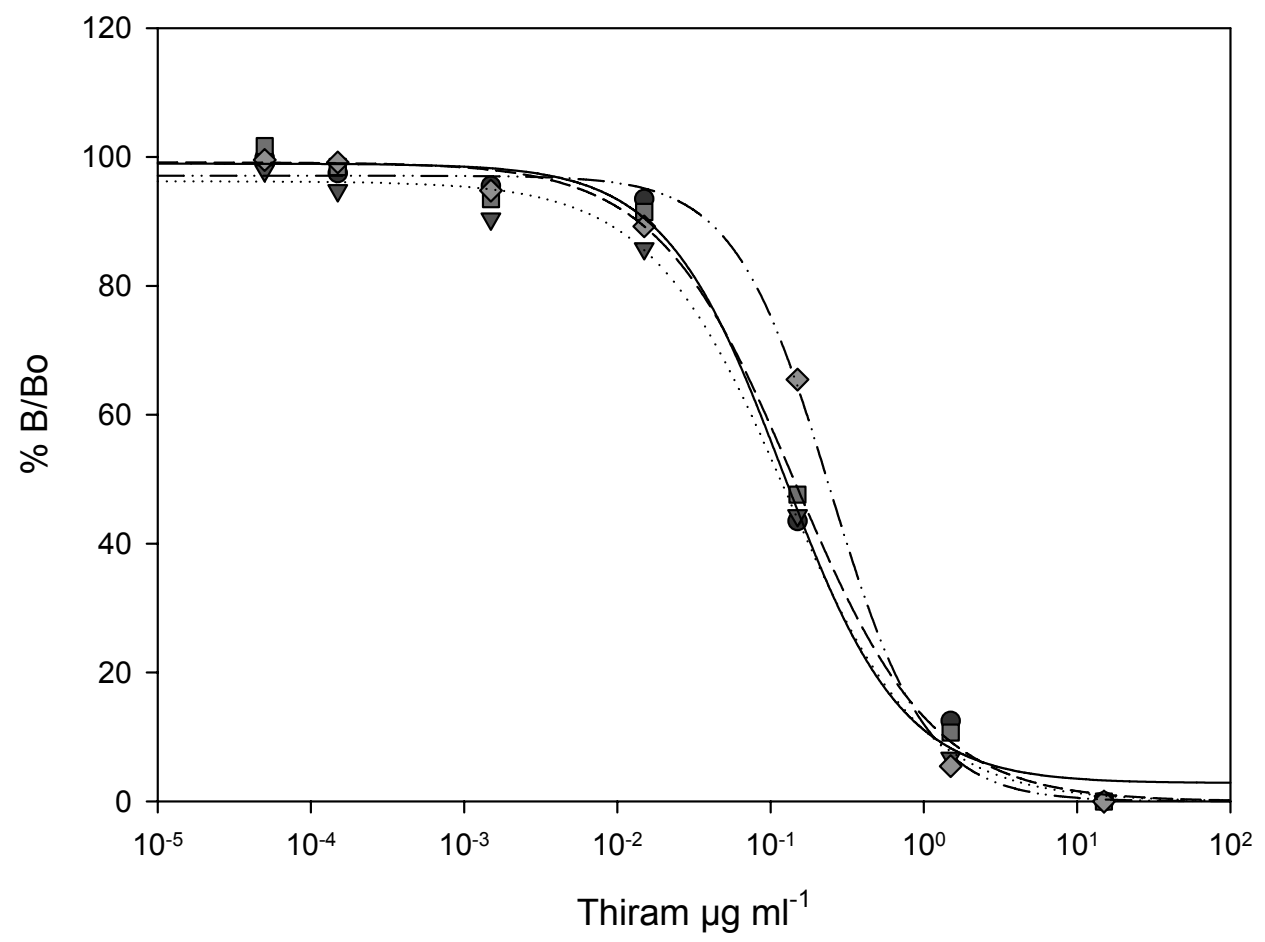

Figure 1B. Influence of methanol concentration on the immunoassay: -•-thiram standards in

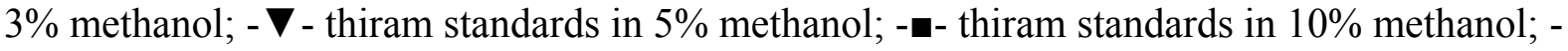
- thiram standards in $20 \%$ methanol. 


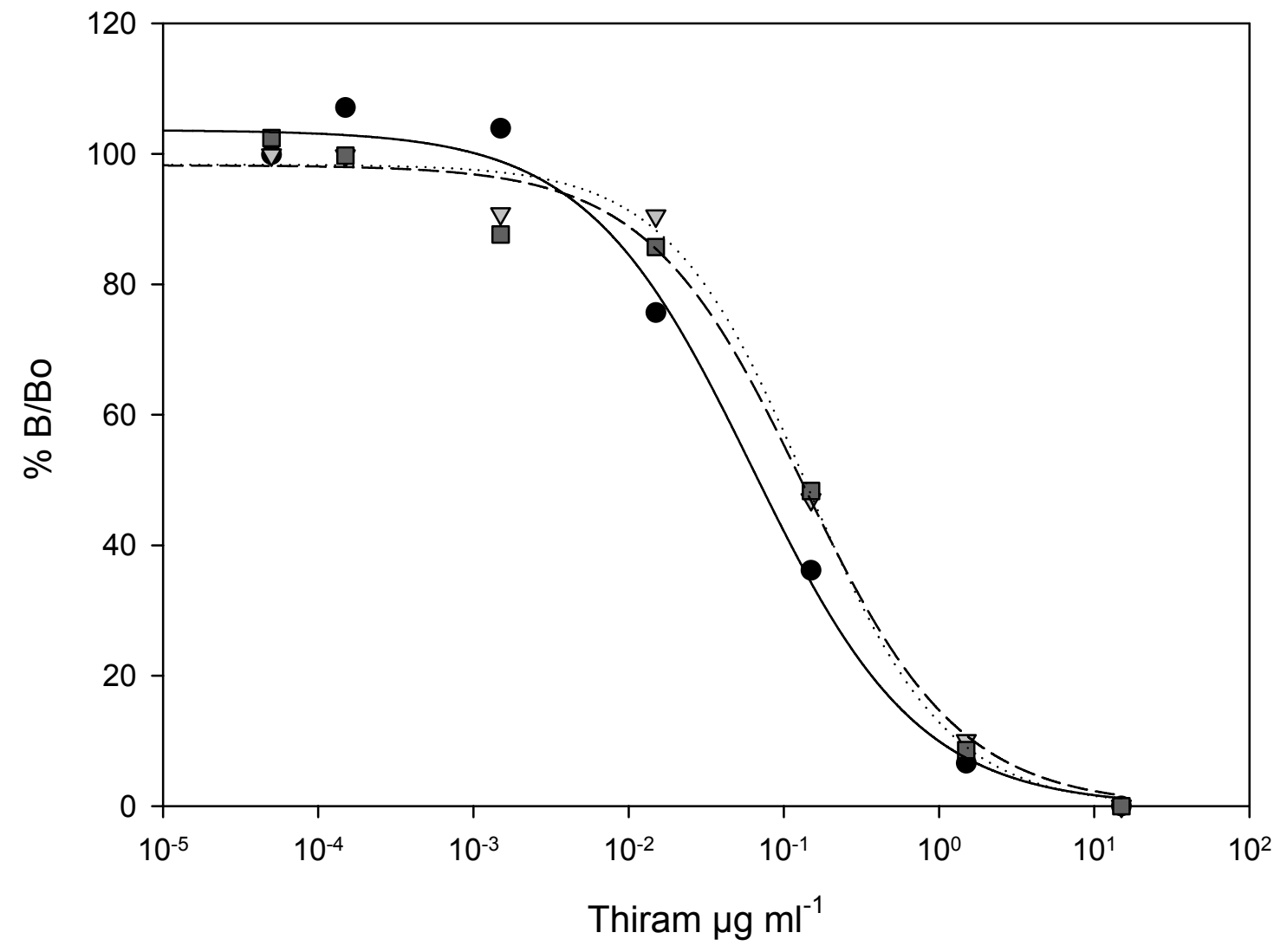

Figure 2. Typical competitive curve for thiram in different solutions: - $\bullet-$ standard prepared in water/acetone; $\mathbf{- \nabla}$ - standard prepared in water/acetone honeybees liquid-liquid extract; standard prepared in water/acetone honeybees graphitized carbon extract. 